\title{
Evaluation of the Possible Immuno-Protective Effect of Nigella Sativa Seed Oil on Cyclophosphamide- Induced Myelosuppression in Mice Shahad A. Hussein ${ }^{* 1}$ and Sarmed H. Kathem ${ }^{* *}$
}

* Ministry of Health and Environment, Medical City Health Directorate, Baghdad, Iraq.

** Department of Pharmacology and Toxicology, College of Pharmacy, University of Baghdad, Baghdad ,Iraq.

\section{Abstract}

Myelosuppression is one of the serious adverse effects of cancer chemotherapy that lead to life threatening febrile neutropenia and considered a limiting factor for successful therapy. Cyclophosphamide a widely used anticancer drugs, induces severe bone marrow suppression by damaging hematopoietic stem cells. As cancer incidence expands globally, the demand for an effective myeloprotective therapy during cancer treatment is also increasing.

Nigella sativa seed oil, a well-known plant extract that widely used for various health conditions. This study aims to evaluate the myeloprotective activity of Nigella sativa seed oil in cyclophosphamide-induced myelosuppression mice model. Myelosuppression induced by single intraperitoneal injection of cyclophosphamide $(200 \mathrm{mg} / \mathrm{kg})$. Animals were divided into 4 groups each with 6 mice. First group served as negative control group received only normal saline. A second group served as experimental myelosuppression model group achieved by cyclophosphamide. Additional 2 groups were mice received Nigella sativa seed oil $(1 \mathrm{ml} / \mathrm{Kg} /$ day) or $(2 \mathrm{ml} / \mathrm{Kg} /$ day) orally for 6 consecutive days starting day 1 with cyclophosphamide on day 3 . Blood were collected from retro-orbital area on day 7 for total and differential leukocytes counts. Compared to model group, it is reported that Nigella sativa seed oil $(1 \mathrm{ml} / \mathrm{Kg})$ significantly $(P<0.05)$ increases total leukocytes count $(1000 \pm 73$ versus $700 \pm 36$ cell $/ \mu \mathrm{L})$ and bone marrow cells viability $(50.17 \pm 5.36$ versus $9.5 \pm 0.76 \%)$. Furthermore, increasing Nigella sativa seed oil dose to $(2 \mathrm{ml} / \mathrm{Kg})$ resulted in further improvement, where we reported a significant $(P<0.05)$ increase in total leukocytes count $(1267 \pm 352$ versus $700 \pm 36$ cell/ $\mu \mathrm{L})$ and bone marrow cells viability $(67.67 \pm 5.49$ versus $9.5 \pm 0.76 \%)$. The study concluded that Nigella sativa seed oil has a promising strong myeloprotective and immunomodulatory effects against cyclophosphamide-induced myelosuppression.

Keywords: Cyclophosphamide, Nigella sativa seed oil, Total leukocytes count, Bone marrow cells viability.

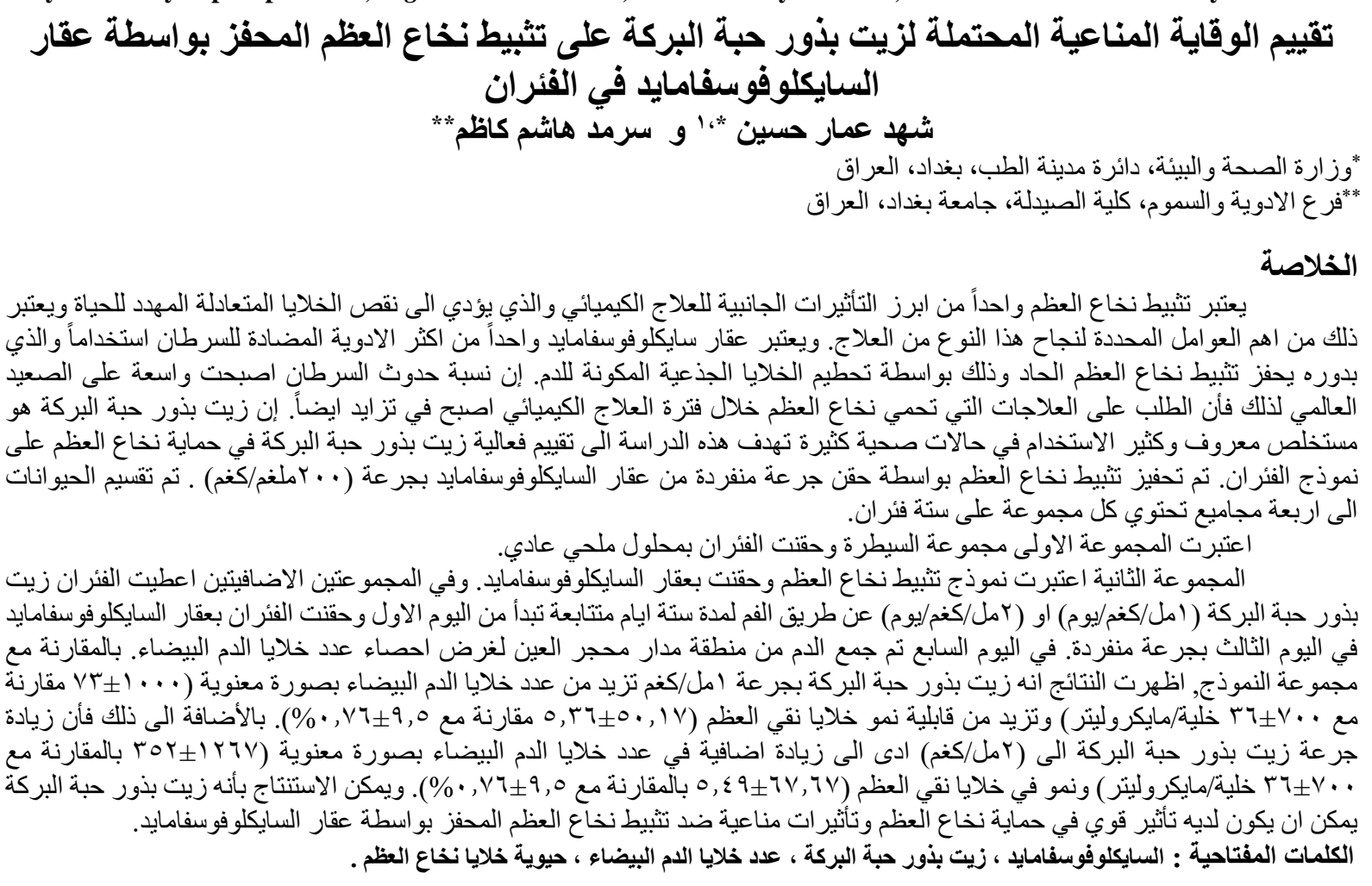

${ }^{1}$ Corresponding author E-mail: shahad.amaar.89@gmail.com

Received: 28/11/2019

Accepted: 1/ 2/2020

Iraqi Journal of Pharmaceutical Scienc 


\section{Introduction}

Bone marrow is the major site that responsible for hematopoiesis by hematopoietic stem cells (HSC) which are continuously proliferating cells that can be differentiated to form different mature blood cells that include red blood cells, white blood cells (granulocytes, monocytes and lymphocytes) and platelets ${ }^{(1)}$. White blood cells (leukocytes) are major part of the immune system that protect the body and defend against pathogens and fight infections. Normal level of total leukocyte count in adult human is $\left(4000-10000\right.$ cells $\left./ \mathrm{mm}^{3}\right)$ ${ }^{(2)}$, while in mice is $\left(2000-10000 \text { cells } / \mathrm{mm}^{3}\right)^{(3)}$.

Myelosuppresion is the most common and popular adverse effect of several chemotherapy which are the most effective therapy for cancer ${ }^{(4)}$. The myelotoxicity caused by cytotoxic drugs lead to dose reductions of these drugs and delays in therapy, these can compromise the outcomes of chemotherapy and reduces overall survival (5,6). Cyclophosphamide (CP) is one of the oldest and the most successful anticancer drugs, it acts as alkylating agent that belong to oxazaphosporines group (7). The initial clinical trials of cyclophosphamide for cancer treatment were performed in 1958, and in 1959 approved by the FDA as a cytotoxic agent. In fact, it is well established that cyclophosphamide is a prodrug metabolize to generate active alkylating metabolites that include 4-hydroxy cyclophosphamide, aldophosphamide mustard, which can interfere with DNA synthesis in rapidly dividing cells and can lead to apoptosis. Cyclophosphamide has toxic effects on different organs that include bone marrow, heart, gonadal and bladder. The main cyclophosphamide toxicity is on bone marrow and bladder ${ }^{(\lambda)}$, the cyclophosphamide myelotoxicity as a result of lack specificity in anti-tumour activity. When killing tumour cells, It also cause serious damage on normal cells, for instance, hematopoietic stem cells which are rapidly dividing cells in the bone marrow, this leads to decrease the ability of these cells to proliferate and differentiate with reduction in the formation of different blood cells. Myelosuppresion can lead to anaemia, leukopenia, and thrombocytopenia. Leukopenia is a life-threatening condition that lead to febrile neutropenia combined with bacterial and fungal infections ${ }^{(9)}$.

Different plants extract found to have a protective effect against a variety of toxicity that induced by chemotherapy ${ }^{(10)}$. Nigella sativa is an annual herb belonging to the Ranunculaceae family. It is also known as (black cumin), the seed have been used as a seasoning spice and food additive in the Middle East and Mediterranean areas ${ }^{(11)}$. Nigella sativa seeds contain proteins, saponins, alkaloids, fixed oil, and essential oil. The biological effects of Nigella sativa are attributed to the various characterized constituents. Thymoquinone (TQ), the main bioactive constituent of the essential oil may be responsible for major therapeutic effects of Nigella sativa ('T). In addition to the seed, its cold pressed oil is utilized as natural dietary supplements and therapeutic agents to support the immune system, treat asthma, allergic rhinitis, diabetes, gastrointestinal disturbance and other conditions in the European Union and other developed countries ${ }^{\left({ }^{r}\right)}$. Nigella sativa seed oil (NG oil) used to evaluate its immune-protective and immunomodulatory effect on myelosuppresion induced by cyclophosphamide. The aim of this study is to evaluate the immune-protective and immunomodulatory effect of Nigella sativa seed oil on cyclophosphamide- induced myelosuppression in mice.

\section{Materials and Methods Animals}

Forty two adults' albino male mice weighing (20-25) gram were brought from and maintained in the Animal House of College of Pharmacy/University of Baghdad under normal conditions of temperature, humidity and light/dark cycle. The animals were fed commercial pellets and tap water ad libitum throughout the experimental period. The study was approved by the Scientificand Ethical-committees of the College of Pharmacy/University of Baghdad.

Drugs

Cyclophosphamide as monohydrate (1000mg vial) was purchased from (Baxter health care Ltd, Germany).

Nigella sativa seed Oil $100 \%$ pure was purchased from Toroslar company (Turkey), which was prepared by cold pressing from fresh Nigella sativa seeds and packaged in amber glass bottle to protect it from sunlight exposure.

\section{Experimental protocol}

Mice were randomly allocated into four groups, each containing 6 mice as follow:

Group I: Mice were received a single intraperitoneal injection of $0.15 \mathrm{ml} 0.9 \%$ normal saline at day 3 . This group served as a negative control.

Group II: Mice were received a single dose of intraperitoneal cyclophosphamide $(200 \mathrm{mg} / \mathrm{kg}$ body weight) on day 3 . This group served as experimental model ${ }^{(14)}$.

Group III: Mice were administered a dose of Nigella sativa seed oil $(1 \mathrm{ml} / \mathrm{Kg}$ body weight/day) orally by oral gavage for 6 consecutive days starting day 1 , with a single dose of intraperitoneal Cyclophosphamide (200mg/Kg body weight) on day 3.

Group IV: mice were orally administered Nigella sativa seed oil at a dose of $(2 \mathrm{ml} / \mathrm{Kg}$ body weight/day) by oral gavage for 6 consecutive days starting day 1 , with a single dose of intraperitoneal Cyclophosphamide (200mg/Kg body weight) on day 3. 
In groups (III and IV) animals, each dose of Nigella sativa seed oil was administered once daily for 6 consecutive days starting day 1 , and on day 3 , they received a single dose of cyclophosphamide (200 mg/Kg body weight) by IP injection. Twentyfour hours after the end of the treatment duration (day 7), the animals were euthanized by diethyl ether (BDH chemicals, England) and cervical dislocation (15).

\section{Samples collection}

\section{1- Blood collection}

After animals have been euthanized on day $7,0.5 \mathrm{ml}$ of blood was drawn from retro-orbital area of mice eyes and collected in EDTA tube. Samples were then prepared for the analysis of total Leukocyte Count ${ }^{(16)}$.

\section{2- Bone marrow extraction.}

After mice euthanized, femur bone was extracted and used to extract bone marrow cells by flushing the marrow cavity with phosphate buffered saline (PBS) PH 7.4 and collected as cell suspension, that was used immediately for bone marrow cell viability test ${ }^{(17,18)}$.

\section{Analysis}

Estimation of total leukocytes count in blood:

Total white blood cells counts were performed on an automated hematology analyzer (XP - 300, sysmex / Japan) using direct detection method ${ }^{(19)}$.

\section{Bone marrow cells viability test}

This test was used to determine the number of viable bone marrow cells present in a cell suspension to the total cell count ${ }^{(20)}$. Equal parts of 0.04\% Trypan blue solution and bone marrow cell suspension were mixed to form a mixture that utilized for counting of the viable cells (clear) and nonviable cells (blue) immediately (within 3-5 minute after mixing) using Neubaur hemocytometer under light microscopy.

Viable bone marrow cells calculated as percentage of total cells. Calculation performed by the following equation:

Viable cells $(\%)=$ [number of viable cells / total number of cells] $* 100$

\section{Statistical analysis}

The numeric data presented in the study expressed as mean \pm standard error of the mean (SE). All statistical analyses were carried out using the Statistical Package of Social Science (SPSS) software version 25. Intergroup comparisons were made using nonparametric tests (Kruskal- Wallis H test, Mann-Whitney $U$ test). Differences were considered significant at $P<0.05^{(21)}$.

\section{Results}

Effect of two doses of Nigella sativa seed oil on total leukocyte count in cyclophosphamide induced myelosuppression.

The data presented in (table 1) and (figure 1) showed that administration of a single dose of intraperitoneal cyclophosphamide $(200 \mathrm{mg} / \mathrm{kg})$ to mice on day 3 (group II, experimental model) resulted in the significant $(P<0.05)$ reduction of total leukocyte count $(700 \pm 36)$ compared to the negative control animals (group I, $5800 \pm 520$ ), that lead to the severe suppression of bone marrow function. However, in group III mice, which administrated Nigella sativa seed oil at a dose of $(1 \mathrm{ml} / \mathrm{Kg} / \mathrm{day}) 3$ days prior to a single intraperitoneal dose of cyclophosphamide $(200 \mathrm{mg} / \mathrm{kg})$ on day 3 resulted in significant attenuation of the cyclophosphamide myelosuppressing effect (table1) (figure 1), the total leukocyte count in those animals (group III) increased $(1000 \pm 73)$ significantly $(P<0.05)$ compared to animals that received cyclophosphamide only (group II, experimental model). Furthermore, increasing the dose of Nigella sativa seed oil to $2 \mathrm{ml} / \mathrm{Kg}$ /day administered 3 days before cyclophosphamide treatment resulted in further improvement of bone marrow function (table1) (figure 1). Data showed that animals received $(2 \mathrm{ml} / \mathrm{Kg} /$ day $)$ of Nigella sativa seed oil (group IV) resulted in significant rise $(P<0.05)$ in total leukocyte count $(1267 \pm 352)$ compared to the experimental model group (group II).

Effect of two doses of Nigella sativa seed oil on bone marrow cells viability in cyclophosphamideinduced myelosuppression.

The data presented in table 1 and figure 2 showed that administration of single intraperitoneal dose of cyclophosphamide $(200 \mathrm{mg} / \mathrm{Kg})$ causes aggressive suppression of bone marrow function manifested as highly significant reduction $(P<0.05)$ in bone marrow cells viability $(9.5 \pm 0.76)$ in the experimental model (group II) compared to the negative control animals ( $92 \pm 0.58$ ) (group I). However, in group III mice received Nigella sativa seed oil at dose of $(1 \mathrm{ml} / \mathrm{Kg} /$ day $) 3$ days prior to $(200 \mathrm{mg} / \mathrm{Kg})$ cyclophosphamide therapy resulted in significant $(P<0.05)$ increase in bone marrow cell viability $(50.17 \pm 5.36)$ compared to model group (group II) (Table 1) (Figure 2). furthermore, Increasing the dose of Nigella sativa seed oil to $(2 \mathrm{ml} / \mathrm{Kg} /$ day) administered 3 days before cyclophosphamide treatment (group IV) resulted in further increase in bone marrow cells viability $(67.67 \pm 5.49)$ and the results appear a significant increase in the viability of bone marrow cells $(P<0.05)$ (group IV) compared to the experimental model group (group II) (Table 1) (Figure2). 
Table 1. Effects of Nigella sativa seed oil on total leukocytes count and bone marrow cells viability in cyclophosphamide-induced myelosuppresion in mice.

\begin{tabular}{|c|c|c|c|}
\hline Groups & Type of treatment & $\begin{array}{l}\text { Total leukocyte } \\
\text { count }(\text { cell/ } \mu \mathrm{L}) \\
(\text { Mean } \pm \text { S.E.M) }\end{array}$ & $\begin{array}{l}\text { Bone marrow Cell } \\
\text { viability }(\%) \\
(\text { Mean } \pm \text { S.E.M) }\end{array}$ \\
\hline $\begin{array}{ll}\text { Group } & \text { I } \\
\text { (negative control) }\end{array}$ & Normal saline & $5800 \pm 520 *$ & $92 \pm 0.58 *$ \\
\hline $\begin{array}{ll}\text { Group } & \text { II } \\
\text { (experimental } & \\
\text { model) } & \end{array}$ & Cyclophosphamide $(200 \mathrm{mg} / \mathrm{Kg})$ & $700 \pm 36$ & $9.5 \pm 0.76$ \\
\hline Group III & $\begin{array}{l}\text { Cyclophosphamide }(200 \mathrm{mg} / \mathrm{Kg}) \\
+\quad \text { Nigella sativa seed oil } \\
(1 \mathrm{ml} / \mathrm{Kg})\end{array}$ & $1000 \pm 73 *$ & $50.17 \pm 5.36^{*}$ \\
\hline Group IV & $\begin{array}{l}\text { Cyclophosphamide }(200 \mathrm{mg} / \mathrm{Kg}) \\
+\quad \text { Nigella sativa seed oil } \\
(2 \mathrm{ml} / \mathrm{Kg})\end{array}$ & $1267 \pm 352 *$ & $67.67 \pm 5.49^{*}$ \\
\hline
\end{tabular}

Data are expressed as mean \pm standard error of means (SEM).

* Significantly different $(P<0.05)$ with respect to the experimental model group.

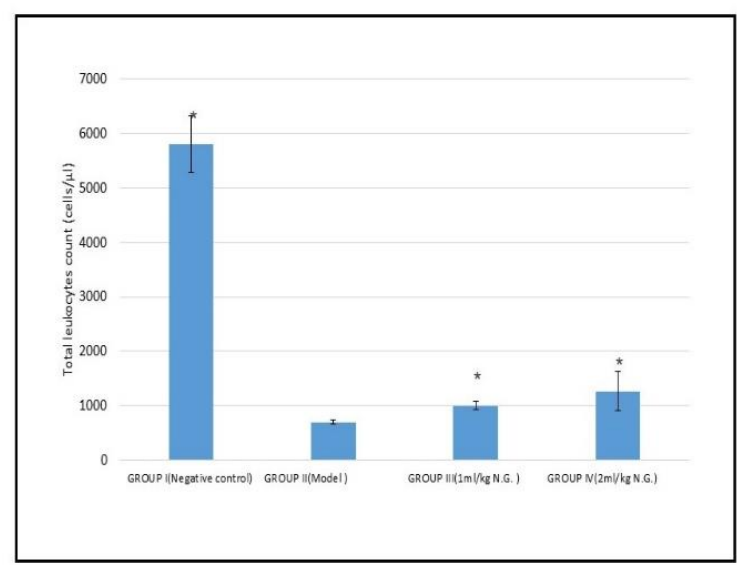

Figure 1. Bar chart showing total leukocytes count in various experimental mice groups.

* Significantly different $(P<0.05)$ with respect to the model group.

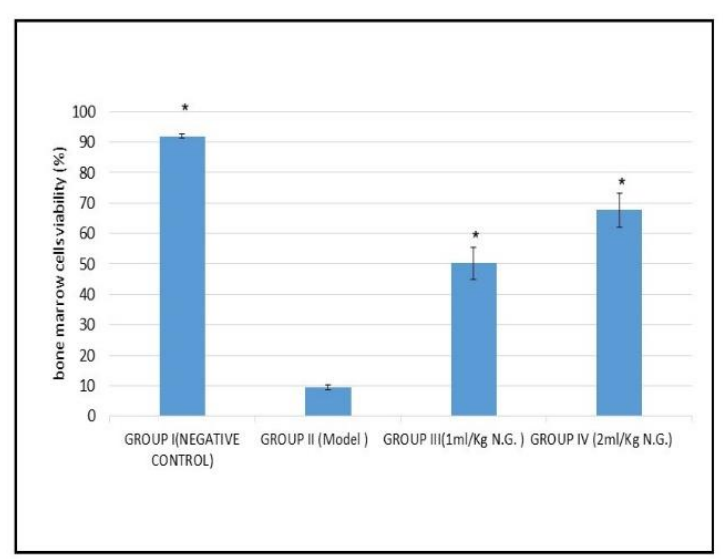

Figure 2.Bar chart showing bone marrow cells viability test in various experimental mice groups.

* Significantly different $(P<0.05)$ with respect to the model group.

\section{Discussion}

Myelosuppression is commonly seen with chemotherapy through interfering with normal cell production in bone marrow leading to myelotoxicity that manifested as a reduction in total white blood cells causing a serious life threatening leukopenia combined with secondary infections (22), so the clinical outcome of treatments with chemotherapy is severely limited, owing to their toxicity to normal tissues. Therefore, there is a necessity to discover adjuvant therapy which may be used in conjunction with anticancer drugs to reduce their associated toxic adverse effect and improve the efficacy of the therapy ${ }^{(23)}$.

The main dose-limiting toxicities for cyclophosphamide are febrile neutropenia combined with secondary infections, often result in dose reductions, therapy delays and lowers overall survival (24).

The current study evaluates the immunuo protective effect of Nigella sativa seed oil on cyclophosphamide-induced myelosuppression. The results obtained from this study revealed a beneficial modulating effect on periphral total leukocytes count and bone marrow cells viability (table 1).

The present study revealed that cyclophosphamide induced myelosuppression, which was evident by the high reduction of total leukocytes count and bone marrow cells viability in animals treated with cyclophosphamide only compared to the negative control animals (Table 1) (Figure 1 and 2) that resulted in aggressive suppression of bone marrow function. The most obviously change in white blood cells count due to their short life cycles; the results are in agreement with studies of other researchers, who observed the myelosuppressive effect of cyclophosphamide administration to animals manifested as reduction of the total leukocyte count after 3-4 days from last cyclophosphamide dosing $(25,14)$. This experimental 
model of cyclophosphamide- induced myelosuppresion is a well validated and widely used animal model to study the effects of chemotherapyinduced myelosuppresion in terms of pathogenesis and therapy $(18,26)$. This study was in line with study of others in cyclophosphamide induced bone marrow suppression by decreasing bone marrow cells numbers in animals treated with cyclophosphamide ${ }^{(27)}$. Data obtained from this study revealed an interesting dose-dependent myeloprotective and immunostimulatory effects of NG oil on bone marrow function. This beneficial effect obtained from the reported increase in total leukocyte count and bone marrow cell viability (table 1), which imply an improvement in bone marrow function after chemotherapy-induced myeosuppression. This is an important result and may open the way for a therapeutic application of NG oil.

This is the first study that investigates the effect of NG oil on bone marrow function in chemotherapy-induced myelosuppresion and there are little studies in this regard. However, NG oil used in other studied showed immunostimulatory actions in experiments with different settings. A study showed increase in the total white blood cells, lymphocyte count and neutrophil count in mice treated with NG oil ${ }^{(28)}$. In addition, other study showed that NG oil has an immunostimulatory effect on Trypanosoma brucei infected animals and revealed a significant rise in total white blood cells of infected animals ${ }^{(29)}$. Another study revealed the immune-potentiation effect of $\mathrm{NG}$ oil in immunocompromised animals by stimulation of macrophage phagocytic activity either directly or via lymphocytes activation (30). Furthermore, the immuno-protective effect of NG oil was observed in gamma-irradiation induced immunusuppression in animals, which considerably normalized leukopenia and produced significant regeneration in spleen and thymus lymphoid follicles (31). The study showed the effect of thymoquinone, the major constituent of NG oil, resulted in increase of the total count of white blood cells in healthy animals which are received specific dose from thymoquinone (32), specific concentration of thymoquinone may regulate self-renewal and immunomodulatory potential of mice bone marrow mesenchymal stem cells in vitro (33). Another study revealed the treatment of animals with NG extract revealed a significant enhancement in the bone marrow cellularity, total leukocyte count and spleen weight compared to normal control animals ${ }^{(34)}$. All the above mentioned studies and results are consistent with the results obtained from this study although each study has its own experimental settings.

On the other hand, some studies showed results in contrast to the results of the current study. In this regard, a study in which type 2 diabetes mellitus patients who received NG oil for 40 days, total leukocyte count remain statistically unchanged (35). Additional study observed a decrease in leukocyte count after chronic treatment of healthy animals with $\mathrm{NG}$ oil for 12 weeks ${ }^{(36)}$. The difference in the results of these two studies may be attributed to the longer duration of treatment with NG oil if compared with current study.

Nigella sativa seed oil pre-treatment was able to protect bone marrow, since it improves bone marrow cells viability and peripheral leukocyte count in cyclophosphamide induced myelosuppresion.

\section{Conclusions}

According to the results obtained from this study, it could be concluded that the Nigella sativa seed oil has a dose-dependent myeloprotective effect on cyclophosphamide-induced myelosuppression in terms of total leukocyte count and cell viability tests. Therefore, Nigella sativa seed oil may have a potential therapeutic value against chemotherapyinduced myelosuppression.

\section{References}

1. Velten L, Haas SF, Raffel S, Blaszkiewicz S, Hennig BP, Hirche C, et al. Human haematopoietic stem cell lineage commitment is a continuous Process. Nat Cell Biol. 2017;19(4):271-81.

2. Sakuragi S, Moriguchi J, Ohashi F, Ikeda M. Reference value and annual trend of white blood cell counts among adult Japanese population. Environ Health Prev Med. 2013;18(2): 143-50.

3. O'Connell KE, Mikkola AM, Stepanek AM, Vernet A, Hall CD, Sun CC, et al. Practical murine hematopathology: A comparative review and implications for research. Comp Med. 2015;65(2): 96-113.

4. Molyneux G, Andrews M, Sones W, York M, Barnett A, Quirk E, et al. Haemotoxicity of busulphan, doxorubicin, cisplatin and cyclophosphamide in the female BALB/c mouse using a brief regimen of drug administration. Cell Biol Toxicol. 2011;27(1): 13-40.

5. Shao L, Wang Y, Chang J, Luo Y, Meng A, Zhou D. Hematopoietic stem cell senescence and cancer therapy-induced long- term bone marrow injury. 2019; 2(5): 397-411.

6. Al-talkani AF, Kathem SH. Prevalence of UGT1A1 * 93 and ABCC5 Polymorphisms in Cancer Patients Receiving Irinotecan-Based Chemotherapy at Al-Najaf Al-Ashraf. Iraqi J Pharm Sci. 2019;28(2):24-9.

7. Ahlmann M, Hempel G. The effect of cyclophosphamide on the immune system: implications for clinical cancer therapy. Cancer Chemother Pharmacol. 2016;78(4):661-71. 
8. Emadi A, Jones RJ, Brodsky RA. Reviews cyclophosphamide and cancer: golden anniversary. Nat Rev Clin Oncol [Internet]. 2009;6(11):638-47.

9. Christen D, Brummendorf TH PJ. [ Leukopenia - A Diagnostic Guideline for the Clinical Routine ]. manual peripheral. Dtsch Med Wochenschr. 2017;142(23):1744-1749.

10. Abdul Jabbar AAS, Kathem SH. The protective effect of Mentha spicata ethanolic extract on irinotecan-induced mucositis in mice. Iraqi $\mathbf{J}$ Pharm Sci. 2019;28(1):37-43.

11. MAJDALAWIEH, Amin F.; FAYYAD, Muneera W. Immunomodulatory and antiinflammatory action of Nigella sativa and thymoquinone: A comprehensive review. International Immunopharmacology, 2015, 28(1): 295-304.

12. Ali BH, Blunden G. Pharmacological and toxicological properties of Nigella sativa. Phyther Res. 2003;17(4):299-305.

13. Ustun Argon Z, Gokyer A. Determination of Physicochemical Properties of Nigella sativa Seed Oil from Balıkesir Region, Turkey. Chem Process Eng Res. 2016;41:43-6.

14. ZHU YL, WANG LY, WANG JX, WANG C, WANG CL, ZHAO DP, et al. Protective effects of paeoniflorin and albiflorin on chemotherapyinduced myelosuppression in mice. Chin J Nat Med. 2016;14(8):599-606.

15. Yang Y, Xu S, Xu Q, Liu X, Gao Y, Steinmetz A, et al. Protective effect of Dammarane Sapogenins against chemotherapy-induced myelosuppression in mice. Exp Biol Med. 2011; 236(6): 729-35.

16. Zuluaga AF, Salazar BE, Rodriguez CA, Zapata AX, Agudelo M, Vesga O. Neutropenia induced in outbred mice by a simplified lowdose cyclophosphamide regimen: characterization and applicability to diverse experimental models of infectious diseases. BMC Infect Dis. 2006; 6: 55.

17. $\mathrm{Xu} \mathrm{SF}, \mathrm{Yu}$ LM, Fan $\mathrm{ZH}, \mathrm{Wu} \mathrm{Q}$, Yuan Y, Wei $\mathrm{Y}$, et al. Improvement of ginsenoside $\mathrm{Rg} 1$ on hematopoietic function in cyclophosphamideinduced myelosuppression mice. Eur J Pharmacol. 2012;695(1-3):7-12.

18. Patra K, Bose S, Sarkar S, Rakshit J, Jana S, Mukherjee A, et al. Amelioration of cyclophosphamide induced myelosuppression and oxidative stress by cinnamic acid. Chem Biol Interact. 2012;195(3):231-9.

19. John W SL. Performance evaluation of the SysmexâXP-300 in an oncologysetting: evaluation and comparison of hematological parameterswith the SysmexâXN-3000. Int Jnl Lab Hem. 2016;38:490-6.

20. Strober W. Trypan Strober. Trypan Blue Exclusion Test of Cell Viability. Current Protocols in Immunology. 1997; 21(1): 1-2.
21. Nachar N. The Mann-Whitney U: A Test for Assessing Whether Two Independent Samples Come from the Same Distribution. Tutor Quant Methods Psychol. 2008;4(1):13-20.

22. Urabe A, et al. Bone marrow suppression. Nihon Rinsho /Japanese J Clin Med. 2003;61(6):949-53.

23. Salem ML, Al-Khami A, El-Nagaar S, Zidan A, Al-Sharkawi I, Marcela Díaz-Montero C, et al. Kinetics of rebounding of lymphoid and myeloid cells in mouse peripheral blood, spleen and bone marrow after treatment with cyclophosphamide. Cell Immunol. 2012; 276(1-2): 67-74.

24. John C B, Andrew E S, John T B, et al. Toxic response of blood. In: Curtis DK, John BW, editors. Casarett and Doulls essentials of toxicology. $3^{\text {rd }}$ ed. United states: Mc grow-hill education; 2015.p. 169-171.

25. Li F, Tang R, Chen LB, Zhang KS, Huang XP, Deng CQ. Effects of Astragalus combined with Angelica on bone marrow hematopoiesis suppression induced by cyclophosphamide in mice. Biological and Pharmaceutical Bulletin. 2017; 40(5): 598-609.

26. Salva S, Marranzino G, Villena J, Agüero G, Alvarez S. Probiotic Lactobacillus strains protect against myelosuppression and immunosuppression in cyclophosphamidetreated mice. Int Immunopharmacol. 2014;22(1):209-21.

27. Xu SF, Yu LM, Fan ZH, Wu Q, Yuan Y, Wei $\mathrm{Y}$, et al. Improvement of ginsenoside $\mathrm{Rg} 1$ on hematopoietic function in cyclophosphamideinduced myelosuppression mice. Eur $\mathbf{J}$ Pharmacol. 2012; 695(1-3): 7-12.

28. Kamil ZH. Effect of Crude Oil of Black Seeds ( Nigella sativa) on White Blood Cell and Hematocrit of Male Albino Mice Treated with Low Toxic Dose of Paracetamol. Med J Babylon. 2013;10(4):1005-12.

29. Ekanem JT, Yusuf OK. Some biochemical and haematological effects of black seed (Nigella sativa) oil on T. brucei-infected rats. African J Biomed Res. 2008;11(1):79-85.

30. Fararh KM, Atoji Y, Shimizu Y, Shiina T, Nikami H, Takewaki T. Mechanisms of the hypoglycaemic and immunopotentiating effects of Nigella sativa L. oil in streptozotocininduced diabetic hamsters. Res Vet Sci. 2004;77(2):123-9.

31. Assayed ME. Radioprotective effects of black seed (Nigella sativa) oil against hemopoietic damage and immunosuppression in gammairradiated rats. Immunopharmacol Immunotoxicol. 2010;32(2):284-96.

32. Jrah Harzallah H, Grayaa R, Kharoubi W, Maaloul A, Hammami M, Mahjoub $T$. Thymoquinone, the Nigella sativa bioactive compound, prevents circulatory oxidative stress 
caused by 1,2-dimethylhydrazine in erythrocyte during colon postinitiation carcinogenesis. Oxid Med Cell Longev. 2012;2012:1-6.

33. Alimoradi E, Sisakhtnezhad S, Akrami H. Thymoquinone influences the expression of genes involved in self-renewal and immunomodulatory potential of mouse bone marrow-derived mesenchymal stem cells in vitro. Environ Toxicol Pharmacol. 2018;60:216-24.

34. Ghonime M, Eldomany R, Abdelaziz A, Soliman H. Evaluation of immunomodulatory effect of three herbal plants growing in Egypt. Immunopharmacol Immunotoxicol. $2011 ; 33$ (1) :141-5.

35. Ahmad B, Masud T, Uppal AM, Naveed AK. Effects of nigella sativa oil on some blood parameters in type 2 diabetes mellitus patients. Asian J Chem. 2009;21(7):5373-81.

36. Zaoui A, Cherrah Y, Mahassini N, Alaoui K, Amarouch H, Hassar M. Acute and chronic toxicity of Nigella sativa fixed oil. Phytomedicine. 2002;9(1):69-74. 